Nuala Cregg fFarCSI, Frances Conway FFarCsI, William Casey FFARCSI

\title{
Analgesia after otoplasty: regional nerve blockade vs local anaesthetic infiltration of the ear
}

\begin{abstract}
Purpose: Children scheduled to undergo otoplasty experience severe pain postoperatively. Nausea and vomiting is also a problem. This study was designed to compare two analgesic techniques (i) regional nerve blockade (ii) local anaesthetic infiltration, with respect to quality and duration of analgesia, opioid requirements and the incidence of postoperative nausea and vomiting (PONV).
\end{abstract}

Methods: Forty three children, ASA I-II, aged 3-15 yr, were studied and followed for $24 \mathrm{hr}$ postoperatively. Patients were randomised into two groups. Patients in Group A received local infiltration with lidocaine $1 \%$ with adrenaline $1: 200,000$ $0.4 \mathrm{ml} \cdot \mathrm{kg}^{-1}(n=21)$. Patients in Group $B(n=22)$ received nerve blockade, bupivacaine $0.5 \%, 0.4 \mathrm{ml} \cdot \mathrm{kg}^{-1}$. No other form of analgesia was used intraoperatively. Quality and duration of analgesia were assessed using pain and sedation scores recorded by a blinded observer at $0,5,10,15,30,45 \mathrm{~min}$ with Recovery Room, and at 0,30,60, 90, 120, 180, 240,360, 480 min on the ward. Pain score $>6$ was treated with fentanyl I $\mu \mathrm{g} \cdot \mathrm{kg}^{-1}$ iv (recovery) and morphine $0.2 \mathrm{mg} \cdot \mathrm{kg}^{-1}$ im or mefenamic acid $8 \mathrm{mg} \cdot \mathrm{kg}^{-1}$ po on the ward. Time to first supplemental analgesia was noted. Mean duration of analgesia was 8.6 (I.I-24) hr, Group A and I0.5 (I.3-24) hr, Group B (P> $0.7) .24 \%$ per cent of children (Group $A$ ) and $27 \%$ (Group B) required no supplemental analgesia $(P>0.6)$. The degree of pain control resulted in a low requirement for opioids, Group A: $24 \%$, Group B: $14 \%$ (P:NS). The overall incidence of PONV was $43 \%$ (Group A) and $36 \%$ (Group B) (P:NS): PONV

\section{Key Words}

ANALGESIA: postoperative;

ANAESTHETIC TECHNIQUE: regional, infiltration; VOMITING: postoperative.

From the Department of Anaesthesia, Children's Research Centre, Our Lady's Hospital for Sick Children, Crumlin, Dublin 12, Ireland.

Address correspondence to: Dr. Nuala Cregg, Department of Anacsthesia, St. James's Hospital. I St. James's Street, Dublin 8, Ireland.

Accepted for publication 5th October, 1995. correlated with opioid use. There were no differences between the groups with regard to pain/sedation scores, quality/duration of analgesia, opioid requirements and incidence of PONV.

Conclusion: Both techniques provided excellent postoperative analgesia. Lidocaine 1\% infiltration (adrenaline $1: 200,000$ ) has the added advantage of improving surgical field and haemostasis. Thus, we advocate use of the simpler technique.

Objectifs: L'otoplastie chez l'enfant provoque des douleurs postopératoires très intenses. De plus, les nausées et les vomissements sont fréquents. Cette étude a permis de comparer deux méthodes d'analgésie: i) le bloc régional avec ii) l'infiltration locale, au regard de la qualité et de l'analgésie, des besoins en morphiniques et de l'incidence des nausées et vomissements postopératoires (NVPO).

Méthode: Quarante-trois enfants ASA I et II âgés de 3 à 15 ans ont été inclus dans l'étude et suivis pendant $24 \mathrm{~h}$ après l'opération. Ils ont été répartis aléatoirement en deux groupes: les patients du groupe $A(n=21)$ ont reçu une infiltration de lidocaïne $1 \%$ adrénalinée à $\mathrm{l}: 200,0000,4 \mathrm{ml} \cdot \mathrm{kg}^{-1}$; ceux du groupe $B(n=22)$, un bloc nerveux à la bupivacaïne $0,5 \%, 0,4 \mathrm{ml} \cdot \mathrm{kg}^{-1}$. Aucune autre forme d'analgésie postopératoire n'a été administrée pendant l'intervention. La qualité et la durée de l'analgésie ont été évaluées sur des échelles de douleur et de sédation et enregistrées par un observateur neutre à $0,5,10,30$ et $45 \mathrm{~min}$ à la salle de réveil et à $0,30,60$, $90,120,180,240,360,480 \mathrm{~min}$ après le retour dans le service. Lorsque les scores de douleur dépassaient 6, l'enfant recevait fentanyl $1 \mu \mathrm{g} \cdot \mathrm{kg}^{-1}$ (salle de réveil) et morphine 0,2 $\mu \mathrm{g} \cdot \mathrm{kg}^{-1}$ im ou de l'acide méfénamique $8 \mathrm{mg} \cdot \mathrm{kg}^{-1}$ po (dans le service). Le moment de l'administration supplément d'analgésique a été noté. La durée moyenne de l'analgésie a été de 8,6 (1,1-24) h pour le groupe $A$; de 10,5 (1,3-24) h pour le groupe $B(P>0,7)$. Vingt-quatre pour cent des enfants du groupe $A$ et $27 \%$ du groupe $B$ n'ont pas eu besoin de supplément d'analgésie $(P>0,6)$. La qualité du contrôle de la douleur permis de réduire les besoins de morphiniques de 24\% dans le groupe $A$ et de $14 \%$ dans le groupe B (P:NS). $L$ 'incidence totale de NVPO a été de $43 \%$ (groupe $A$ ) et de 
$36 \%$ (groupe B) (P:NS). On a trouvé une corrélation entre les NVPO et les morphiniques. Il n'y a pas eu de différences entre les groupes au regard des scores de douleur et de sédation, de la qualité et la durée de l'analgésie, des besoins en morphiniques et de l'incidence de NVPO, les deux techniques procurant une analgésie postopératoire excellente.

Conclusion: L'infiltration de lidocaïne $1 \%$ adrénalinée à I:200,000 a l'avantage de faciliter la technique chirurgicale et de favoriser l'hémostase. Les auteurs conseillent d'utiliser cette technique parce qu'elle est la plus simple.

Children with unduly prominent ears, "bat ears," are likely to suffer from teasing by other children because of this deformity, with resultant psychological trauma. Surgical correction, otoplasty, is the only treatment. This procedure is associated with severe pain and a high incidence of postoperative nausea and vomiting (PONV). ${ }^{1.2,4}$ The use of opioid analgesics for pain relief increases the incidence of PONV.'

The pinna of the ear is supplied by the cervical plexus and the trigeminal nerve. ${ }^{7}$ The posterior surface and the lower third of the anterior surface are supplied by the great auricular and the lesser occipital nerves, branches of the cervical plexus. These nerves become subcutaneous at the junction of the middle and upper thirds of the sternomastoid muscle. The superior two thirds of the anterior surface is supplied by the auriculotemporal nerve, a branch of the mandibular division of the trigeminal. (Figure 1)

Analgesia may be successfully achieved by blocking the nerve supply to the ear. ${ }^{1.3}$ Infiltration of the ear with local anaesthetic solution containing adrenaline, performed by the surgeons to reduce blood loss and improve haemostasis may, in addition, provide analgesia which extends into the postoperative period. ${ }^{2}$

This study was designed to compare regional nerve block, using bupivacaine $0.5 \%$ to local anaesthetic infiltration of the ear, using lidocaine $1 \%$ with adrenaline $1: 200,000$, with respect to the quality and duration of analgesia, opioid requirements and incidence of PONV.

\section{Methods}

With Hospital Ethics Committee approval and informed parental consent, 43 children, ASA class I-II, aged 3-15 years, scheduled to undergo bilateral otoplasty, were enrolled in the study. The children were randomised to receive either local anaesthetic infiltration (Group $A$ ) or regional nerve blockade (Group B).

General anaesthesia was standardised. Premedication was with oral trimeprazine $2 \mathrm{mg} \cdot \mathrm{kg}^{-1}$ (weight $<35 \mathrm{~kg}$ ) or oral diazepam $0.2 \mathrm{mg} \cdot \mathrm{kg}^{-1}$ (weight $>35 \mathrm{~kg}$ ). Anaesthesia was induced with sodium thiopentone 5-6

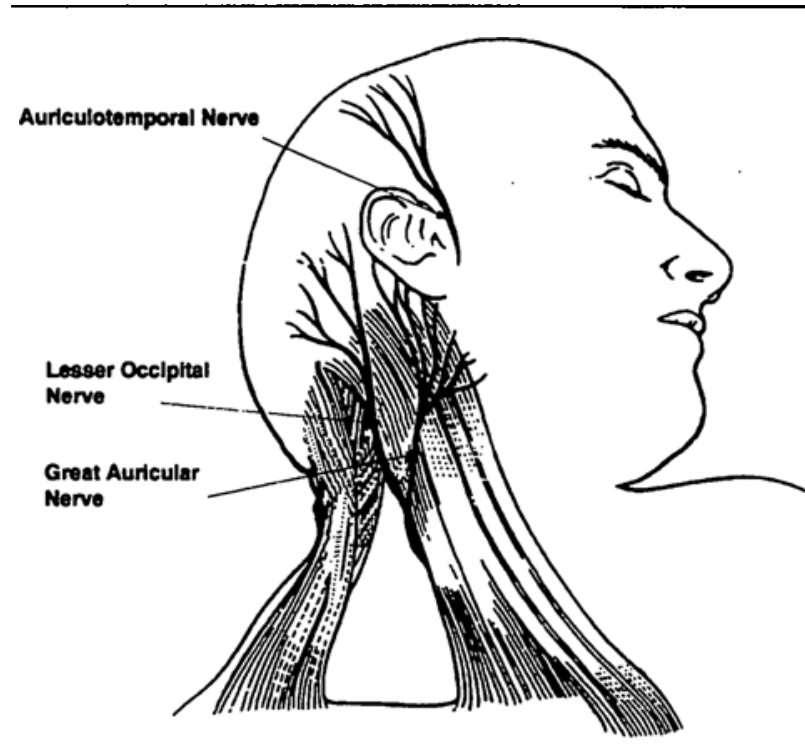

FIGURE 1 The pinna of the car is supplied by the great auricular and the lesser occipital nerves, branches of the cervical plexus, and the auriculotemporal nerve, a branch of the mandibular division of the trigeminal nerve.

$\mathrm{mg} \cdot \mathrm{kg}^{-1}$ iv or inhalation induction with $50 \%$ oxygen/nitrous oxide and halothane $4 \%$ according to the child's preference. Tracheal intubation was achieved under deep halothane anaesthesia and anaesthesia was maintained with oxygen/nitrous oxide and halothane $0.5-1 \%$. All children were allowed to breathe spontaneously, the inspired concentration of halothane titrated to maintain haemodynamic variables within $20 \%$ of preoperative levels. An Ayre's T-piece with Jackson Rees' modification was used for children whose weight was $<25 \mathrm{~kg}$, a Bain's breathing system (Mapleson D) was used for children whose weight was $>25 \mathrm{~kg}$, the fresh gas flow used being sufficient to prevent rebreathing. Intraoperative monitoring included non-invasive arterial blood pressure, ECG, pulse oximetry and end-tidal capnography.

After induction of anaesthesia and ten minutes before surgical incision, local anaesthetic infiltration or regional nerve blockade, was performed bilaterally by the anaesthetist. In Group A, using a $23 \mathrm{G}$ hypodermic needle, $0.4 \mathrm{ml} \cdot \mathrm{kg}^{-1}$ lidocaine $1 \%$ (adrenaline $1: 200,000$ ), was infiltrated subcutaneously into the anterior and posterior aspects of the pinna. In Group B, regional nerve blockade was performed bilaterally, using a $25 \mathrm{G}$ spinal needle, injecting $0.4 \mathrm{ml} \cdot \mathrm{kg}^{-1}$ bupivacaine $0.5 \%$, subcutaneously from the angle of the mandible to the mastoid process, blocking the great auricular and lesser occipital nerves, with injection over the posterior aspect of the zygoma, in order to block the auriculotemporal nerve 


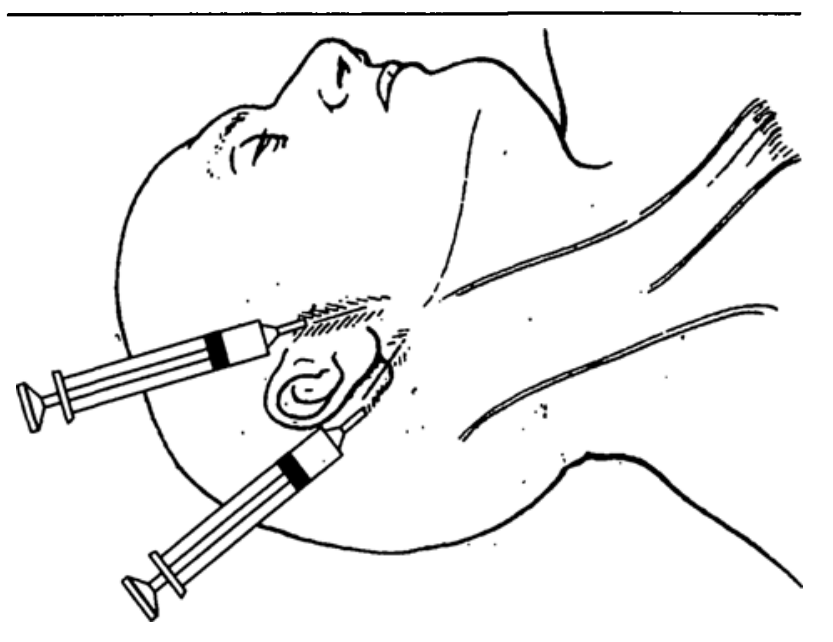

FIGURE 2 Regional anaesthesia of the ear. The great auricular and the lesser occipital nerves are blocked by infiltration posterior to the car, from the angle of the mandible to the mastoid process. The auriculotemporal nerve is blocked by infiltration over the posterior aspect of the zygoma.

(Figure 2). In Group B the ear was infiltrated with 0.4 $\mathrm{ml} \cdot \mathrm{kg}^{-1} \mathrm{NaCl} 0.9 \%$, containing adrenaline 1:200,000, to improve haemostasis. No other form of analgesia was used intraoperatively.

The children were assessed in the recovery room at 0 , $5,10,15,30,45 \mathrm{~min}$ and on the ward at $0,30,60,90$, $120,180,240,360,480 \mathrm{~min}$.by a blinded observer and followed for a total of $24 \mathrm{hr}$ postoperatively. Pain and discomfort were assessed using the Objective Pain Scale (Table I), which equates pain and discomfort with changes in such physiological variables as blood pressure, crying, movement, agitation and verbal evaluation of pain (Scale 0-10). Any child with a pain score $>6$ in the recovery room received fentanyl $1 \mu \mathrm{g} \cdot \mathrm{kg}^{-1} i v$. On the ward a pain score $>6$ was treated with either mefenamic acid $8 \mathrm{mg} \cdot \mathrm{kg}^{-1}$ po or morphine $0.2 \mathrm{mg} \cdot \mathrm{kg}^{-1} \mathrm{im}$, according to the severity of the pain and the ability of the child to tolerate fluids orally. Analgesia was administered whenever pain scores exceeded 6 and was independent of the planned pain and sedation assessment time. Time to first supplemental analgesia was noted. Sedation score (Steward's Criteria) ${ }^{6}$ assessed airway, movement and responsiveness in recovery (Scale 0-6). Alertness on the ward was assessed on a scale of 1-4. The occurrence of nausea and vomiting was recorded and treated with cyclizine $0.75 \mathrm{mg} \cdot \mathrm{kg}^{-1}$ im as required.

\section{Statistical analysis}

Demographic data were compared using Students $t$ test. Pain and sedation scores, analgesic requirements, occurrence of vomiting and correlation between vomiting and
TABLE I Objective Pain Scale (Broadman et al.) equating pain and discomfort with changes in physiological variables.

\begin{tabular}{ll}
\hline Blood Pressure & \\
$\pm 10 \%$ pre op & 1 \\
$>10-20 \%$ pre op & 2 \\
$>20-30 \%$ pre op & \\
Crying & 0 \\
Not crying & 1 \\
Crying responds to TLC & 2 \\
Crying, no response to TLC & \\
Movement & 0 \\
None & 1 \\
Restless & \\
Thrashing & 2 \\
Agitation & \\
Aslecp or calm & 0 \\
Mild & 1 \\
Hysterical & 2 \\
Verbalises pain & \\
Aslcep or says no pain & \\
Cannot localise pain & 1 \\
Can localise pain & 2 \\
\hline
\end{tabular}

TABLE II Demographic data. Results expressed as mean (SD).

\begin{tabular}{lll}
\hline & $\begin{array}{l}\text { Lidocaine infiltration } \\
\text { (Group A) } \\
n=21\end{array}$ & $\begin{array}{l}\text { Bupivacaine block } \\
\text { (Group B) } \\
n=22\end{array}$ \\
\hline Age (yr) & $8.4 \pm 3.1$ & $9.5 \pm 3.3$ \\
Weight (kg) & $25.6 \pm 8.6$ & $30.7 \pm 10.2$ \\
Sex (M/F) & $15 / 6$ & $11 / 11$ \\
\hline
\end{tabular}

opioid use - were analysed using Mann Whitney $U$ test. Time to first supplemental analgesia based on specific time intervals postoperatively $(<2,2-4,4-8,8-24,>24$ hr) was compared using Chi-squared analysis. Time to first supplemental analgesia based on each individual child's first specific request for supplement analgesia was analysed with the use of 1-tailed, unpaired t-test. Statistical significance was $P$ value $<0.05$.

\section{Results}

There were no differences between groups with regard to demographic data, (age, weight and sex) (Table II). There were no differences between groups with regard to type of premedication, induction strategy and halothane concentration used. The type of premedication used depended on the child's weight $(P=0.09)$. The type of induction depended on the age of the child $(P=0.28)$ and the child's preference. The halothane concentration was maintained between $0.5-1 \%$ for all children during the study period. 


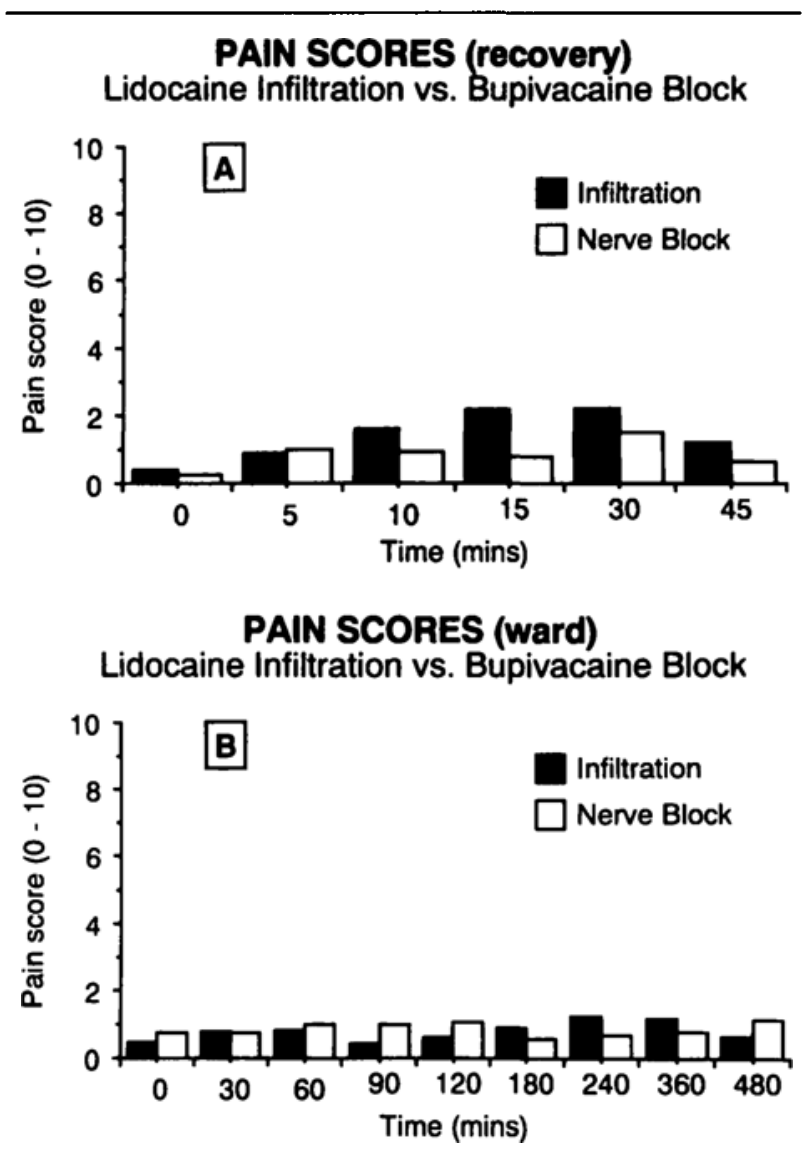

FIGURE 3 Mean pain scores recorded in (A) the recovery room ( 0 , $5,10,15,30,45 \mathrm{~min})$ and $(B)$ on the ward $(0,30,60,90,120,180$, $240,360,480 \mathrm{~min}$ ). Pain scores were low in both groups, differences between groups were non significant, recovery $(P: N S)$ and ward $(P: N S)$.

Both techniques provided excellent and comparable pain relief as shown by the low pain scores and low requirements for opioid analgesia. (Figure 3). Pain scores were low in both groups, differences between groups were non significant, recovery $(P>0.35)$, ward $(P>0.15)$. Pain score $<4$ was recorded in $62 \%$ of children in Group $A$ and $86 \%$ of children in Group B, throughout the study period. Sedation scores were comparable, both groups demonstrating rapid recovery $(P>$ $0.5)$.

Mean duration of analgesia in Group A was 8.6 (1.1-24) hr, mean duration of analgesia in Group B was 10.5 (1.3-24) hr $(P>0.7)$ (Figure 4). There were no differences between groups with regard to the type of postoperative analgesia (opioid vs. mefenamic acid) (Figure 5 ). There was a low requirement for opioid analgesia in this study: $24 \%$ of children in Group $A$ and $14 \%$ in Group B required opioids (fentanyl) in the recovery room. Analgesic requirements on the ward were adequately treated with the non-steroidal anti-inflammatory
TIME TO FIRST SUPPLEMENTAL ANALGESIA Lidocaine Infiltration vs. Bupivacaine Block

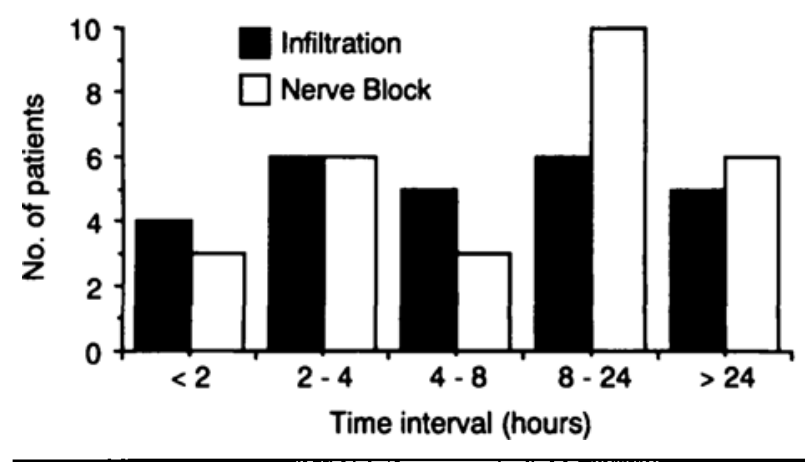

FIGURE 4. Time to first supplemental analgesia. Time intervals are represented in hours $(<2,2-4,4-8,8-24,>24 \mathrm{hr}) .24 \%$ of children in Group A (infiltration) and $27 \%$ in Group B (nerve block) required no supplemental analgesia postoperatively, analgesia extending beyond $24 \mathrm{hr}$.

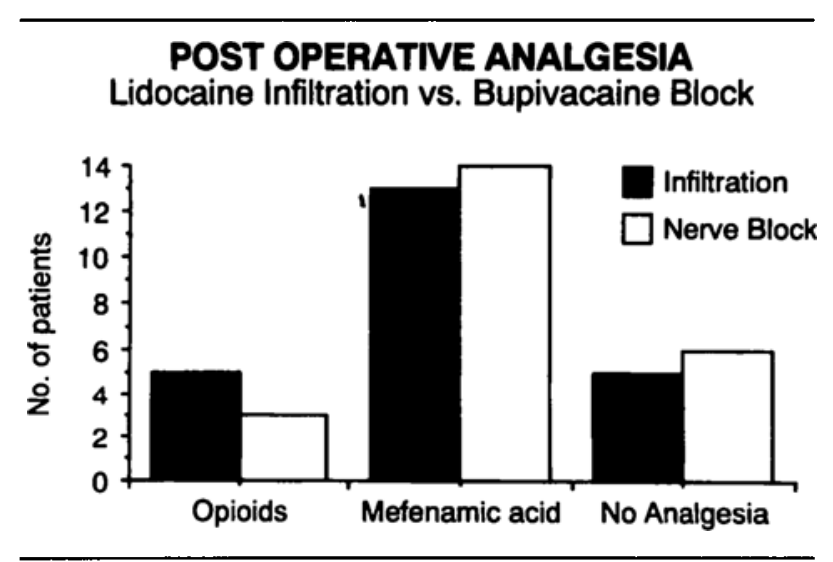

FIGURE 5 Postoperative analgesia. There were no differences between groups with regard to type of analgesia required postoperatively (opioids vs. mefenamic acid) ( $P: \mathrm{NS}$ ). $24 \%$ of children in Group $A$ (infiltration) and $14 \%$ in Group $B$ (nerve block) required opioids in the recovery room. No child required opioid analgesia on the ward.

drug, mefenamic acid. No child required opioid analgesia (morphine) on the ward: $24 \%$ of children in Group A and $27 \%$ of children in Group B required no supplemental analgesia postoperatively, analgesia from regional nerve blockade or local anaesthetic infiltration extending beyond $24 \mathrm{hr}(P>0.6)$.

The overall incidence of postoperative nausea and vomiting in this study was $43 \%$ in Group $A$ and $36 \%$ in Group B ( $P:$ NS). The association between PONV and $(P>0.6)$ opioid usage is illustrated in Table III. The incidence of PONV in association with opioids was $60 \%$ in Group A and $100 \%$ in Group B. When opioids were not used the incidence of PONV was $38 \%$ in 
TABLE III Incidence of postoperative nausea and vomiting (PONV) - association between PONV and opioid use.

\begin{tabular}{lll}
\hline & $\begin{array}{l}\text { Lidocaine infiltration } \\
\text { (Group A) } \\
n=2 I\end{array}$ & $\begin{array}{l}\text { Bupivacaine block } \\
\text { (Group B) } \\
n=22\end{array}$ \\
\hline PONV (ovcrall incidencc) & $9 / 21(43 \%)$ & $8 / 22(36 \%)$ \\
PONV (+ opioid) & $3 / 5(60 \%)$ & $3 / 3(100 \%)$ \\
PONV (no opioid) & $6 / 16(38 \%$ & $5 / 19(27 \%)$ \\
\hline
\end{tabular}

Group A and 27\% in Group B. These figures suggest a difference in incidence of PONV between children receiving opioids and those not receiving opioids however the numbers are too small to permit statistical analysis.

\section{Discussion}

Otoplasty is an elective cosmetic procedure performed on healthy children and should, therefore, be associated with minimal morbidity. Unfortunately this is not the case, severe pain and a high incidence of PONV make the child's first postoperative day particularly distressing. ${ }^{1.2,4}$ Opioid analgesics compound the problem of PONV, ${ }^{1,2}$ cause excessive sedation and delay early resumption of oral fluids.

Alternative methods of providing postoperative pain relief are regional analgesia ${ }^{8.9}$ and local anaesthetic infiltration. ${ }^{10.11}$ The success of regional nerve blockade in the management of pain post otoplasty has been demonstrated. ${ }^{1}$ Local anaesthetic infiltration of the pinna using lidocaine $1 \%$ with adrenaline is performed routinely by the surgeons in our hospital in order to reduce bleeding at the surgical site during otoplasty. Local anaesthetic infiltration should, in addition, provide postoperative analgesia. In our hospital regional nerve blockade using bupivacaine $0.5 \%$ is performed routinely by the anaesthetist. The aim of this study was to compare two analgesic techniques already in use in our hospital with regard to quality and duration of analgesia, opioid requirements and incidence of PONV.

In our study we found that both techniques provided excellent and comparable analgesia. Mean duration of analgesia was $8.6(1.1-24) \mathrm{hr}$ in the group that received lidocaine $1 \%$ infiltration (Group A). Mean duration of analgesia was $10.5(1.3-24) \mathrm{hr}$ in the regional nerve blockade group (Group B). The degree of pain control achieved by both regional nerve blockade and local anaesthetic infiltration resulted in a low requirement for opioids in this study, $24 \%$ of children in Group A (infiltration) and $14 \%$ in Group B (nerve block). Interestingly, 24\% of children in Group $A$ and $27 \%$ of children in Group B required no supplemental analgesia postoperatively, analgesia extended beyond $24 \mathrm{hr}$.
Burtles et al.' found that by blocking the great auricular and lesser occipital nerves, there was a reduction in opioid use, with a concomitant reduction in the incidence of PONV compared with a control group of children. The block was performed using bupivacaine $0.25 \%$ or $0.5 \%$, to a maximum of $2 \mathrm{mg} \cdot \mathrm{kg}^{-1}$ on 42 children in the study group. They found that $95 \%$ of children in the control group (no block) $(n=21)$ required postoperative opioids compared to $9.5 \%$ of children in the blocked group $(n=42)$.

A previous study performed in our hospital by Doyle et al., compared regional nerve blockade with placebo injection. ${ }^{5}$.This study demonstrated a significantly lower mean dose requirement for opioids in the study group as compared to the control group. Mean dose (sd) of fentanyl required was $0.73(0.51) \mu \mathrm{g} \cdot \mathrm{kg}^{-1}$ in the study group $(n=21)$ and $2.28(1.82) \mu \mathrm{g} \cdot \mathrm{kg}^{-1}$ in the control group $(n=25)(P<0.01)$. Interestingly, $75 \%$ of children in the study group required opioids despite regional nerve blockade, however the mean dose of opioid required was less than the controls.

Factors which might account for the large number of children $(75 \%)$ in the study group of Doyle et al. requiring opioids compared with our study and that of Burtles et al. are as follows: (i) restlessness and agitation, the result of emergence from anaesthesia, compounded by the presence of a tight turban bandage, misinterpreted as pain could account for the high opioid use. In our study, one child in Group A (local anaesthetic infiltration), received fentanyl $\left(1 \mu \mathrm{g} \cdot \mathrm{kg}^{-1}\right)$ in the recovery room, and was discharged the following morning having requested no further analgesia. Presumably the fentanyl was administered inappropriately. (ii) premedication - children in our study were premedicated with either oral trimeprazine or diazepam, similarly $37 / 42(88 \%)$ children in the study by Burtles et al. were premedicated, in the study by Doyle $e t$ al. all children were unpremedicated (iii) we used a larger volume of bupivacaine $0.5 \%$ to perform the block, $0.4 \mathrm{ml} \cdot \mathrm{kg}^{-1}$ compared with 0.2 $\mathrm{ml} \cdot \mathrm{kg}^{-1}$ in the study by Doyle et al. (iv) finally we blocked the auriculotemporal nerve in addition to the great auricular and lesser occipital nerves.

The overall incidence of PONV in our study was $43 \%$ in Group A (infiltration) and $36 \%$ in Group B (nerve block) ( $P$ :NS) Five children in Group A required opioid analgesia, $3 / 5(60 \%)$ vomited postoperatively. Three children in Group B required opioids, 3/3 (100\%) vomited postoperatively. When opioids were not used in the postoperative period, 6/16 (38\%) children in Group A and $5 / 19(27 \%)$ children in Group B experienced PONV. In addition children who received opioids experienced a greater number of emetic episodes. In our study there appears to be a correlation between opioid 
use and PONV (Table III), confirming the findings of Burtles et al., however numbers are too small to permit statistical analysis. Burtles $e t$ al. found a decrease in the incidence of PONV, with $85 \%$ (18/21) of children in the control group experiencing PONV and only $48 \%$ (20/42) in the blocked group vomiting postoperatively.

According to Wood et al. ${ }^{12}$ the half life $\left(\mathrm{T}_{1 / 2}\right)$ of bupivacaine is considerably longer than that of lidocaine ( 2.7 $\mathrm{hr}$ vs $1.6 \mathrm{hr}$ ). The duration of action of bupivacaine is $3.3 \mathrm{hr}$ whereas the duration of action of lidocaine is 1.25 $\mathrm{hr}^{12}$ The addition of adrenaline to lidocaine prolongs the duration of action from $1.25 \mathrm{hr}$ to $6.6 \mathrm{hr}$ because of vasoconstriction. ${ }^{12}$ Surgeons often make use of this property by infiltration of the surgical site with adrenaline containing solutions in order to reduce bleeding and improve haemostasis. Roberts et $a .^{2}{ }^{2}$ compared local anaesthetic infiltration of the ear using lidocaine $1 \%$ (adrenaline 1:200,000) to infiltration using bupivacaine $0.25 \%$ (adrenaline 1:400,000) and found a statistically significant decrease in opioid requirements in the first 4 hr postoperatively in the bupivacaine group $(P<0.05)$. All patients however received rectal paracetamol (20 $\mathrm{mg} \cdot \mathrm{kg}^{-1}$ ) at completion of surgery. The addition of adrenaline to bupivacaine has not been shown to prolong its duration of action. ${ }^{12}$

Mean duration of analgesia in our study was 8.6 (1.1-24) hr in Group A and 10.5 (1.3-24) hr in Group B. Interestingly $24 \%$ of children in Group A (local anaesthetic infiltration) and $27 \%$ in Group B (nerve block) required no supplemental analgesia postoperatively, analgesia extending beyond $24 \mathrm{hr}$. Since regional nerve blockade and local anaesthetic infiltration were performed before surgical incision and tissue trauma, pre-emptive analgesia may have accounted for duration of analgesia exceeding the pharmacological duration of action of the drugs. ${ }^{14-19}$ To quote Wall et al. "pre-emptive preoperative analgesia has prolonged effects which long outlast the effect of drugs". 14 "Pre-emptive analgesia" is a new approach to the management of postoperative pain, whereby analgesic agents (opioids, local anaesthetics or non-steroidal anti-inflammatory drugs) are administered before surgical incision in an effort to prevent nerve impulses arising from the incision, reaching and sensitising central neural structures involved in pain perception. ${ }^{19}$

In conclusion, this study demonstrates that local anaesthetic infiltration using lidocaine $1 \%$ (adrenaline $1: 200,000$ ) and regional nerve block using bupivacaine $0.5 \%$ are effective and comparable forms of analgesia post otoplasty, with a low requirement for opioids and a low incidence of PONV in the absence of opioids. There were no differences between the groups with regard to pain and sedation scores, quality and duration of analge- sia, opioid requirements and incidence of PONV. Local anaesthetic infiltration of the pinna is easy to perform, requiring no great technical skill. Infiltration can be achieved anteriorly and posteriorly with a single injection. If an adrenaline containing solution is used there are the added advantages of reducing intraoperative bleeding, improving haemostasis and providing a degree of hydrodissection facilitating surgery.

Regional nerve blockade appears to be superior to local infiltration since injections are directed specifically at the nerves supplying the pinna. Regional nerve block, however requires skilled hands and careful monitoring. Two injections are required to block all three nerves. It provides no haemostasis and no degree of hydrodissection. Finally with regional nerve block there is the possibility of local anaesthetic spreading from the subcutaneous tissues into the deeper planes of the neck, especially in young children, with the risk of vascular spread and even the remote chance of phrenic nerve blockade. Therefore we advocate use of the simpler technique, local anaesthetic infiltration.

\section{References}

1 Burtles $R$. Analgesia for 'bat ear' surgery. Ann R Coll Surg Engl 1989; 71: 332

2 Roberts $R H$, Tan ST, Sinclair SW. Lignocaine vs bupivacaine in prominent ear correction: a controlled trial. $\mathrm{Br} \mathbf{J}$ Plast Surg 1992; 45: 533-5.

3 Reeves G. Bat ears without tears (Editorial). Lancet 1989; 1: 1193.

4 Sossai R, Johr M, Kistler W, Gerber H, Scharli AF. Postoperative vomiting in children. A persisting unsolved problem. Eur J Pediatr Surg 1993; 3: 206-8.

5 Doyle M, Casey W, Pollard V, Smith J, Moore KP, Mannion $D$. Efficacy of local analgesia in postoperative pain for otoplasty. Anesthesiology 1992; 77: A1 190.

6 Steward DJ. A simplified scoring system for the postoperative recovery room. Can Anaesth Soc J 1975; 22 : 111-3.

7 Backhouse KM, Hutchings RT. A Colour Atlas of Surface Anatomy. London: Wolfe Medical 1986; 42-3.

8 Broadman $L M$. Regional anaesthesia in paediatric practice. Can J Anaesth 1987; 34: S43-8.

9 Yaster M, Maxwell LG. Paediatric regional anaesthesia. Anesthesiology 1989; 70: 324-38.

10 Munroe I. Analgesia in children after day-case surgery (Editorial). Lancet 1988; 1: 1084-5.

11 Reid MF, Harris R, Phillips PD, Barker l, Pereira NH, Bennet NR. Day-case herniotomy in children. A comparison of ilio-inguinal nerve block and wound infiltration for postoperative analgesia. Anaesthesia 1987; 42: 658-61.

12 Wood M, Wood A. Drugs and Anesthesia - Pharmacology 
for Anesthesiologists. 2nd ed. Baltimore: Williams \& Wilkins Publishers, 1990: 341-2

13 Ganong WF. Review of Medical Physiology. 14th ed. Connecticut: Appleton \& Lange Publishers (Division of Prentice Hall), 1989: 112-7.

14 Wall PD. The prevention of postoperative pain (Editorial). Pain 1988; 33: 289-90

15 Breivik $H$. Pre-emptive analgesia. Current Opinion in Anaesthesiology. 1994; 7: 458-61.

16 Woolf CJ, Chong M-S. Preemptive analgesia - treating postoperative pain by preventing the establishment of central sensitization. Anesth Analg 1993; 77: 362-79.

17 Dahl JB, Kehlet $H$. The value of pre-emptive analgesia in the treatment of post operative pain. Br J Anaesth 1993; 70: 434-98.

$18 M c$ Quay HJ. Pre-emptive analgesia (Editorial). Br J Anaesth 1992; 69: 1-3.

19 Katz J. Preop analgesia for postop pain. Lancet 1993; 342: 65-6. 